\title{
CASTABILITY OF CORROSION-RESISTANT SUPERALLOYS
}

Michae1. R. Edwards

Metallurgy Branch, Royal Military College of Science, Shrivenham

The castability of a high-boron alzoy B1925 was found to be better than the conventional alzoys IN 738 and IN 792. To test whether the absence of carbides in B1925 or the increased volume of liquid solidifying as eutectic was responsible for the improved castability, carbon-free samples of IN 738 and IN 792 were cast. B1925 still showed superior castability, which suggests that the increased volume of eutectic is the primary cause of its improved castabizity.

The presence of porosity in cast turbine blades is undesirable. Macroporosity causes an increase in the number of rejected castings, while micro-porosity produces an increase in the scatter of creep-rupture properties, especially at the high stress - moderate temperature $\left(700-850^{\circ} \mathrm{C}\right)$ condition encountered in cooled blades. While the level of porosity is principally a function of the component geometry and the casting conditions (metal temperature, mould temperature, mould material), some alloys seem to have intrinsically better castability than others. Using such alloys should produce reduced scrap rates, and, with the reduction of microporosity, increases in design stresses or extensions of component lives.

The aim of the current work is to examine corrosion-resistant superalloys in order to discover what determines castability.

\section{EXPERIMENTAL}

Four a11oys were used. Except for B1925, which was initially available only in bar-stock form, the alloys had 
Table 1. Chemical Composition (weight per cent) of Alloys investigated.

\begin{tabular}{|l|ccccccccccc|}
\hline & B & C & Co & Cr & Mo & W & Ta & A1 & Ti & Zr & Others \\
\hline IN 738 & 0.002 & 0.16 & 8.3 & 16.2 & 1.7 & 2.7 & 1.7 & 3.6 & 3.5 & 0.08 & $1.0 \mathrm{Nb}$ \\
IN 792(A) & 0.005 & 0.08 & 9.1 & 12.5 & 1.9 & 4.1 & 4.0 & 3.4 & 3.4 & 0.04 & \\
IN 792(C) & 0.005 & 0.14 & 9.2 & 12.6 & 2.0 & 3.8 & 4.0 & 3.5 & 3.5 & 0.11 & 1.1 Hf \\
B 1925 & 0.104 & 0.015 & 8.6 & 11.7 & 1.8 & 4.5 & 4.0 & 3.4 & 3.4 & 0.006 & \\
\hline
\end{tabular}

Table 2. Chemical Composition (weight per cent) of Alloys in Second Series.

\begin{tabular}{|l|ccccccccccc|}
\hline & B & C & Co & Cr & Mo & W & Ta & A1 & Ti & Nb & Zr \\
\hline IN 738 & 0.002 & 0.16 & 8.3 & 16.2 & 1.7 & 2.7 & 1.7 & 3.6 & 3.5 & 1.0 & 0.08 \\
IN 738VLC & 0.005 & 0.015 & 8.5 & 15.6 & 1.7 & 2.5 & 1.9 & 3.4 & 3.4 & 0.9 & 0.08 \\
IN 792VLC & 0.005 & 0.025 & 8.9 & 12.5 & 2.0 & 4.0 & 4.4 & 3.2 & 3.8 & - & 0.03 \\
B1925 & 0.1 & 0.027 & 8.4 & 11.6 & 1.8 & 4.4 & 4.0 & 3.5 & 4.0 & - & 0.01 \\
\hline
\end{tabular}

been remelled into separately cast test bars. The composition of the alloys are in Table 1 .

Sma11 specimens were heat-treated for thirty minutes at temperatures between solidus and liquidus and quenched into water. Photomicrographs were taken and the percentage liquid measured from the photomicrographs using an Optomax inage analyser. Additionally changes in microstructure between liquidus and solidus were noted. Some specimens were heated to $1400^{\circ} \mathrm{C}$ to ensure dissolution of carbides, cooled in the furnace to temperatures below the liquidus and then quenched in water. These were then microscopically examined in order to estimate the temperature of carbide formation.

A second series of specimens nominally free of carbon, with compositions as in Table 2, was prepared and heat-treated in the same way. All were in the form of solid turbine blades, and measurements were taken from the thickest section of the ae rofoil.

The castability of the second series alloys was determined by cutting up cast turbine blades and examining with a Quantimet image analyser the polished sections for microporosity. 


\section{RESULTS AND DISCUSSION}

\section{Microstructural Examination}

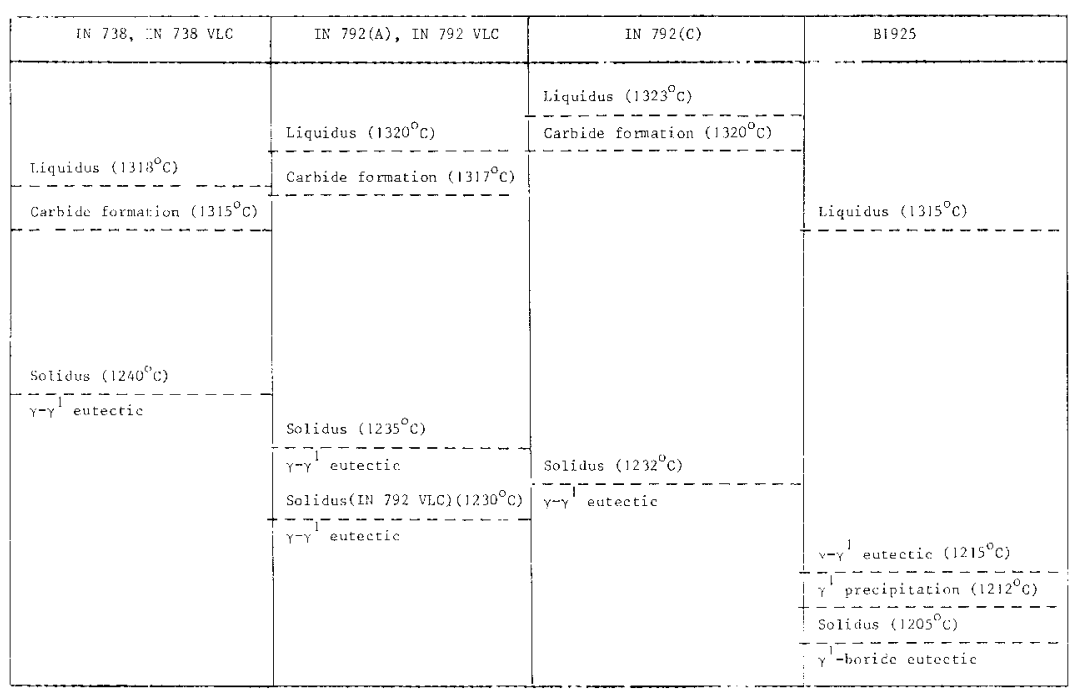

TEMPERATURES ALE $+r_{1}^{\circ} \mathrm{C}$

Fig. 1. Changes in microstructure between liquidus and solidus.

Fig. I shows that B1925 has a larger freezing range than the other alloys, and that there are two eutectics, which appear as discrete pools of $\gamma / \gamma^{\prime}$ eutectic and $\gamma^{\prime} /$ boride eutectic within the eutectic areas. The temperature difference $\left(10^{\circ} \mathrm{C}\right)$ between the $\gamma / \gamma^{\prime}$ eutectic and the $\gamma^{\prime} /$ boride is less than the $73^{\circ} \mathrm{C}$ reported for $\mathrm{B} 1914$, the high boron analogue of IN 100 (1). Carbide formation temperatures for the carbon-containing alloys are all very close to the liquidus, and the possibility that the carbides are the first part of the alloy to solidity cannot be ruled out.

The volume percentage liquid that freezes in a eutectic manner is about 6-8\% for B 1925, while the other three alloys have up to $2 \%$ freezing in this way. This is shown in Fig. 2. 


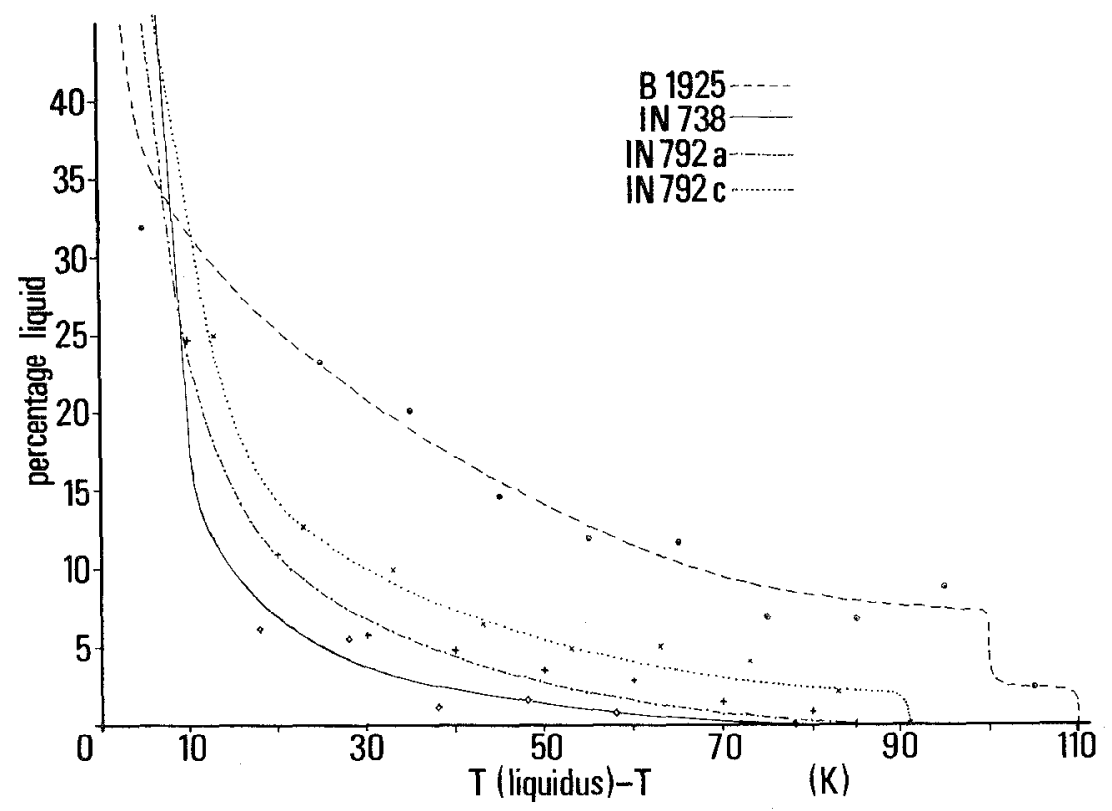

Fig. 2. Volume of Liquid during Solidification.

When the results of the carbon-free alloys, shown in Fig. 3, are examined, it can be seen that the percentage of liquid solidifying as a eutectic is increased from nil to $2 \%$ for IN 738 , and from 1 to $2 \%$ for IN 792 . These are comparable to the hafnium-containing IN $792(\mathrm{C})$ shown in Fig. 2, but still much less than that for B 1925 . 
M. R. Edwards / 299

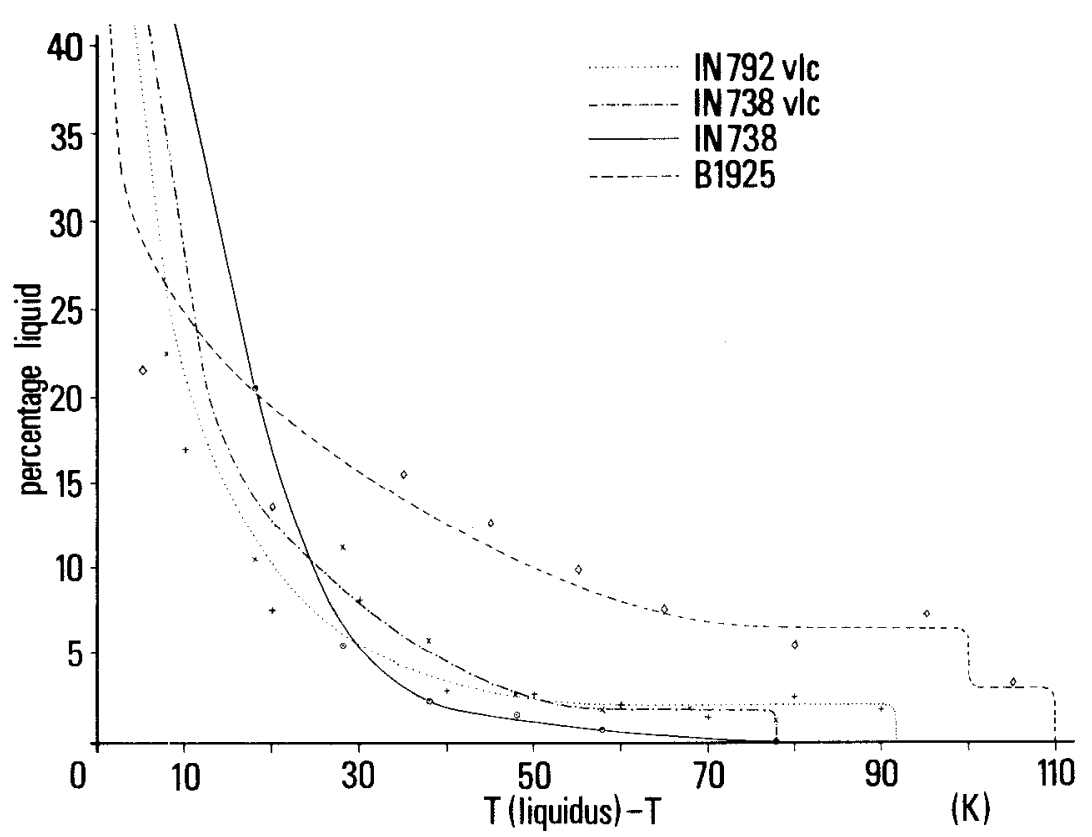

Fig. 3. Volume of Liquid during Solidification.

Castability

Assessment of the microporosity of the four alloys of the first series (2) showed that IN 738, IN 792(A) and IN 792(C) had comparable moderate castability, while B1925 had much superior castability. Microporosity in the three former alloys was associated with the interdendritic and intergranular regions, while what microporosity existed in B 1925 was in the eutectic pools. These results are similar to those in the literature $(3,4)$.

Two possible reasons for the improved castability have been proposed (1). Firstly, the carbide particles which form at or near the liquidus can impede the flow of liquid through the capillaries that exist in the inter-dendritic regions at temperatures close to the solidus. Secondly, following Flemings (5), the microporosity can be reduced by reducing the pressure drop $(\Delta \mathrm{P})$ that exists in the liquidsolid region. This pressure drop is inversely proportional to the square of the volume fraction of the liquid, and directly proportional to the rate of solidification and the 
shrinkage occurring on solidification. If, assuming, as the casting conditions are the same, that the rate of solidification is the same, and, in the absence of data, that the shrinkage for all the alloys considered in this work is the same, then the pressure drop given by Equation 1

$$
\Delta \mathrm{P} \quad \alpha \frac{1}{\mathrm{~V}_{1 i q}} \quad \mathrm{~V}_{1 i q}=\text { volume fraction liquid }
$$

for B1925 should be 5-10 times smaller than for any of the other alloys.

It was decided to measure the incidence of microporosity in alloys of the second series, which included carbon-free versions of IN 738 and IN 792. The results of the assessment are shown in Table 3. As before, the microporosity in the low-boron alloys were interdendritic, while that of B1925 was associated with the eutectic pools. From this it can be seen that the two carbon-free low boron alloys (IN 738VLC and IN 792VLC) have an incidence of microporosity which is comparable to the conventional IN 738 , rather than to B1925.

Table 3 Assessment of Microporosity

\begin{tabular}{|l|c|c|c|c|c|c|}
\hline \multirow{2}{*}{ Alloy } & \multicolumn{3}{|c|}{$\begin{array}{c}\% \text { of sections with } \\
\text { moderate porosity }\end{array}$} & \multicolumn{3}{|c|}{$\begin{array}{c}\% \text { of sections with } \\
\text { severe porosity }\end{array}$} \\
\cline { 2 - 7 } & Root & Aerofoil & Shroud & Root & Aerofoil & Shroud \\
\hline B1925 & 0 & 2 & 19 & 0 & 0 & 6 \\
IN738 VLC & 55 & 71 & 38 & 40 & 10 & 44 \\
IN792 VLC & 65 & 50 & 50 & 30 & 23 & 44 \\
IN738 & 67 & N/A & 42 & 13 & N/A & 17 \\
\hline
\end{tabular}

A11 specimens cast into the form of RB21l IP blades. Metal termerature $1500^{\circ} \mathrm{C}$, loose-backed mould at $1070^{\circ} \mathrm{C}$.

Moderate porosity - worst field $(1.25 \mathrm{~mm} \times 1.0 \mathrm{~mm})$ of microsection has $\geqslant 0.2 \%$ porosity.

Severe porosity - worst field of microsection has $\geqslant 1.0 \%$ porosity.

No results for the aerofoil in IN738 available, as the sectioning plan of the blade is not the same. 
The incidence of severe porosity shown in Table 3 for IN 738 VLC and IN 792VLC is somewhat higher than for IN 738, but it must be remembered that assessments of microporosity can be variable, and more moulds would be needed to be certain that the low carbon alloys are more prone lo severe microporosily.

The measurements of microporosity on the carbon-free alloys has shown that the primary reason for the increased castability of B1925 is the increased volume of liquid which solidifies close to the solidus. What cannot be deduced is whether an alloy which has a high volume percentage of $\left(\gamma-\gamma^{\prime}\right)$ eutectic would have as good castability as the high boron - low carbon alloys with their $\left(\gamma-\gamma^{\prime}\right)$ and $\left(\gamma^{\prime}\right.$-boride) eutectics. The absence of carbide particles does not seem to affect the castability to any extent.

\section{CONCLUSIONS}

The improved castability of B1925, compared with conventional corrosion-resistant superalloys, is associated with the increased volume percentage of liquid solidifying as a eutectic, rather than to the absence of carbide particles.

\section{ACKNOWLEDDGEMENTS}

T wolld like to thank Ro11s-Rnyce Limited for casting the carbon-free alloys and carrying out the microporosity assessments, and Sorcery Metals for the initial gift of B1925. Particular thanks are due to Tony Denton, Peter Bye, Brian Cooper and Robert Hill of Rolls-Royce for their help, and to Roger England of RMCS for experimental assistance.

\section{REEERENCES}

(1) E. Bachalet and G. Lesoult in "High Temperature Alloys for Gas Turbines" ed. D. Coutsouradis et al., Applied Science Publishers (1978), .665-99.

(2) Rolls-Royce Limited, unpublished work.

(3) C. A. Hammersley, Metallurgia, Feb 1978, p.105.

(4) G. L. R. Durbar in "High Temperature Alloys for Gas Turbines" ed. D. Coutsouradis et a1., Applicd Science Publi.shers (1978), p.45?-465.

(5) M. C. Flemings, "Solidification Processing", McGraw-Hil1 $(1974), p .235$. 